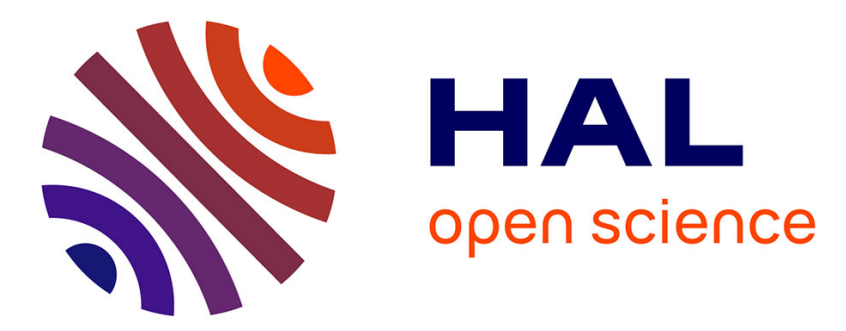

\title{
Electron-microscopic analysis of polymer switching thin films
}

\author{
V. Kornilov, A. Lachinov
}

\section{To cite this version:}

V. Kornilov, A. Lachinov. Electron-microscopic analysis of polymer switching thin films. Journal de Physique IV Proceedings, 1993, 03 (C7), pp.C7-1585-C7-1588. 10.1051/jp4:19937249 ～jpa-00251887

\section{HAL Id: jpa-00251887 https://hal.science/jpa-00251887}

Submitted on 1 Jan 1993

HAL is a multi-disciplinary open access archive for the deposit and dissemination of scientific research documents, whether they are published or not. The documents may come from teaching and research institutions in France or abroad, or from public or private research centers.
L'archive ouverte pluridisciplinaire HAL, est destinée au dépôt et à la diffusion de documents scientifiques de niveau recherche, publiés ou non, émanant des établissements d'enseignement et de recherche français ou étrangers, des laboratoires publics ou privés. 


\title{
Electron-microscopic analysis of polymer switching thin films
}

\author{
V.M. KORNILOV and A.N. LACHINOV
}

Physics Department, Ufa Research Centre, Acad. Sci. of Russia, K. Marx Str. 6, Ufa 450025, Russia

This paper presents results of the electron-microscopic analysis of poly (3,3'-phthalidylidene-4, $4^{\prime}$-biphenylylene)s (PPB) thin films with anomalously high spontaneous conductivity. The conductive state of the polymer is shown to be due to the formation of areas of high conductivity about $50-100 \mathrm{~nm}$ in size which join into larger clusters. It was established that the microscopic relief of the polymer film and its inherent texture exert no effect on the processes of switching and generation of the conductive structure.

The problem of the nature of the anomalousiy high sensitivity of the PPB conductivity to uniaxial pressure (1-3) has not yet been solved. The study of this phenomenon is complicated by the fact that it is observed in thin films, specifically, in polypropylene $d<100 \mathrm{~mm}$ while in PPB d<1 mm. High anisotropy of conductivity and small size of the conducting domain of the polymer film create additional difficulties for the study of the electron instability in such objects. Besides, there is no convincing information on the structure and topology of electrically conducting phase. So far, it has been studied only by indirect methods, such as spreading of current (4), method of liquid crystals (5), or statistic methods (6). Hence, the present paper conveys results of the electron-microscopy analysis of the conductive structure geometry in PPB thin films.

Films of a polyaromatic compound PPB were used for the investigation, for all the above listed phenomena were earlier displayed by polymers of that type. Moreover, PPB is a soluble and heat resistant polymer, which makes it very convenient for the 
investigation. Polymer films of thickness 50-100 nm were prepared by spin coating the polymer solution on a copper electrode deposited on a polished glass plate.

We applied the following method of decorating the conducting structure with metal atoms. The presence of electrically conducting areas in the polymer dielectric matrix was supposed to create substantial non-equilibriun for the diffusion of metal atoms from the electrode into the film. According to (1), the domain conductivity can be as high as $10^{5} \mathrm{~cm} / \mathrm{cm}$. Hence, according to (4), the recorded resistance of the sample is the spreading resistance arising in the point where the conducting area contacts with the electrode. In other words, it is at this very contact site that the Joule heat is emitted during the flow of current. This heating can be sufficient for melting the electrode at the contact site if it is made of a lowmelting-point material such as indium or the wood alloy.

There mast probably be a certain boundary separating the conducting area from the non-conducting matrix and, like at any boundary, the concentration of defects there will be higher than its average value. These were the reasons why we expected the rate of the electrode metal atom diffusion in conducting areas of 1 ilm to be higher than that in dielectric ones.

Pigure 1 shows a photograph of the polymer film in an electron microscope after its diffusional decoration with the indium atoms.

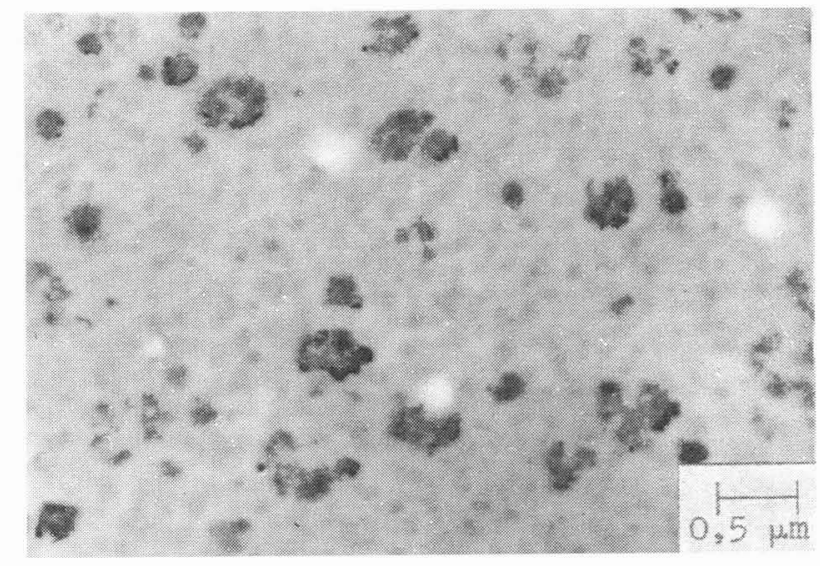

Fig. 1 Metalic inclusions in polymer film resulting from difiusional decoration. Magnification $\mathrm{x} 20,000$. 
It should be noted that decoration occurs only in the conducting state of the polymer film and is due to the prolonged (6-8 hours) joint effect of temperature and flowing current. If the polymer is in a dielectric state, no decoration occurs, all the other conditions being the same.

There are areas in the sample that have substantially different electron-optical contrast, which can be explained by the pile-ups of metal atoms there. The size of these areas varies from 0.5 to $1 \mathrm{\mu m}$ and they consist of the clusters of metallic inclusions of smaller sizes. The metallic inclusions in the film are probably due to both the diffusion of metal into the polymer and metal particles welded to the polymer surface on sites where current flows.

Besides the metallic inclusions, there is also a texture with the structural element size ranging from 0.1 to $0.5 \mu \mathrm{m}$ resulting from the orienting effect of micro-relief on the electrode surface. Thus, a polymer replica of the electrode is formed. There is a clear dependence of the structural element size on the conditions of the lower electrode preparation. The fact that the micro-relief is nowhere but on the electrode surface is confirmed by the comparison of the polymer replica with the carbon replica, taken off a different part of the same electrode, There is a clear dependence of the structural element size on the conditions of the lower electrode preparation. The appearance of the polymer replica being typical of replicas with altermating thickness and its relief (of the "cobbles" type) being totally analogous to that, revealed by the carbon replica. The sizes of metallic inclusions resulting from the diffusion partially correspond to the sizes of the relief structural elements.

The performed experiments have convincingly proved that the metal atorn diffusion into the polymer film is not at all an easy process. Traces of diffusion can be seen only after the film have been exposed to electric current and temperature for many hours. Single switching of film under pressure or in electric field causes neither change in the film structure not its failure.

However, the discovered texture of the polymer film and its relation to the texture of the substrate pose the problem of the effect of the electrode relief on the process of polymer film switching. To solve this problem, we carried out experiments on switching a film prepared on an electrode made of a different 
material (geld). In this case, no electrode rellel has been observed during the observation of the polymer replica though switching to the conducting state occurs at the same values of the applied pressure and field. To aroid possible influence of the electrode relief on the formation of polymer film, we prepared samples cast on the water surface and then placed on a gold electrode, switching to the conducting state being similar to that in the previous experiment.

Hence, it can be concluded that the conducting state of a PPB film is not the result of the direct contact of electrodes because of the film defects or the penetration of electrod material into film, but is due to the existence of highly conducting areas (domains) in the polymer matrix. The distribution of these channels in the film is independent of the substrate relief and of the way the film was prepared and does not correlate with the inherent film structure though the average sizes of the conducting channels coincide with the mean sizes of the free film structural domains.

\section{ACKNOWLEDGHIRNIS}

Te would like to express our sincere gratitude to Dr. H. Zolotukhin for providing high quality polymer samples

\section{References}

[1] ZHEREBOV A. Yu., and IACHINOV A. N., Synth. Ket. 44 (1991) 99.

[2] IAACHINOV A. N., ZHEREBOV A. Yu., and KORAIIOV V. M., Synth. Het., 44 (1991) 111.

[3] ZHEREBOV A. Yu., IACHINOV A. N., Synth. Metals. 46 (1992) 181.

(4) ARKHANGORODSKIY v. u., IONOV A. N., TUCHKEVICH $\nabla$. M., and SHLIMAK I. S., Pisma Y ZRIF, 51 (1990) 56.

[5] KORNIIOV V. M., IAGHINOV A. N., Synthetic Metalls, 53 (1992) 71.

[6] SMIRNOVA S. G., GRIGOROV I. N., GALASHINA N. M., and ENIKOIOPIAN N. S., DOklady AN SSSR, 288 (1986) 176. 